\title{
Equality for Prospective People: A Novel Statement and Defence
}

\author{
Alex Voorhoeve* (D) \\ Department of Philosophy, Logic and Scientific Method, London School of Economics and Political \\ Science, London, United Kingdom \\ ${ }^{*}$ Corresponding author. Email: a.e.voorhoeve@lse.ac.uk
}

\begin{abstract}
A possible person's conditional expected well-being is what the quality of their prospects would be if they were to come into existence. This article examines the role that this form of expected well-being should play in distributing benefits among prospective people and in deciding whom to bring into existence. It argues for a novel egalitarian view on which it is important to ensure equality in people's life prospects, not merely between actual individuals, but also between all individuals who, given our choices, have a chance of coming into existence. The article argues that such egalitarianism for prospective people springs from equal concern for each prospective person and has plausible implications. It further shows that it has a rationale in respect for both the unity of the individual and the separateness of persons. Finally, it defends this view against a key objection and shows it is superior to a rival view.
\end{abstract}

\section{Introduction}

When we consider possible future people, we take an interest in what their prospects would be if they came into existence. For example, in 2019, there was widespread reporting of the UK Office for National Statistics's estimates for the life expectancy of babies born in the UK between 2019 and 2043. One headline-grabbing finding was that, due to a slowing of the estimated rate of health improvements, the prospects of future people had worsened: the projected life expectancy of a baby born in 2019 had decreased since the previous estimate (which was done in 2015) from 91.6 to 89.1 and the projected chance of a baby born in 2043 reaching the age of 100 had been slashed from $34.1 \%$ to $23.4 \%$. A second much-discussed finding was the inequality in the projected life expectancy of girls and boys, with boys born in 2019 projected to live, on average, 2.6 years fewer than girls, and boys born in 2043 projected to have a 5.3\% lower chance than girls of reaching $100 .^{1}$ In this article, I refer to the quality of a person's prospects, should they be born, as their 'conditional expected well-being'. I examine the role that the quality of such prospects, as well as the inequality in such prospects,

\footnotetext{
${ }^{1}$ James Gallagher, Child Life Expectancy Projections Cut by Years, BBC News website, 2 December 2019 $<$ https://www.bbc.co.uk/news/health-50631220> [last accessed 28 May 2020].

(C) The Author(s), 2021. Published by Cambridge University Press. This is an Open Access article, distributed under the terms of the Creative Commons Attribution licence (http://creativecommons.org/licenses/by/4.0/), which permits unrestricted re-use, distribution, and reproduction in any medium, provided the original work is properly cited.
} 
should play in moral decision-making. I develop and defend an egalitarian view on which we have special reason to improve the prospects of those possible people whose expectations, conditional on existence, are worse than those of other people who have a chance of coming into existence. Importantly, I shall argue, we have this reason even in the absence of any inequality between co-existents.

In section 1, I argue that when deciding on prospective people's fates, it matters whether we are engaged in intrapersonal trade-offs or in interpersonal trade-offs. In section 2, I propose a novel extension of a familiar pluralist egalitarian view. I argue that this novel view coheres with egalitarian ideals and adequately handles both types of trade-off. In Section 3, I defend this view's focus on a person's conditional prospects rather than on their chance of coming into existence. In section 4 , I consider and reject the claim, advanced by Jake Nebel, that this view can select an alternative which is guaranteed to generate worse outcomes than another feasible alternative. In section 5, I consider Nebel's rival non-egalitarian view and argue that it fails to respect the difference between intra- and interpersonal trade-offs. ${ }^{2}$ I offer my conclusions in section 6 and a formal account of the proposed view in an Appendix.

Before proceeding, let me mention some basic assumptions of my analysis. The theory I develop is designed for so-called 'same actual number, variable-identity' cases, in which a fixed number of people will exist, but the identities of these people may vary. I do so in order to extend familiar theories of distributive morality (which usually deal only with 'same actual number, fixed-identity' cases) by one step into a relatively novel area of application without dealing with the well-known challenges of variable actual number population ethics. ${ }^{3}$ (The proposed theory does, however, cover cases in which the number of people who have a chance of coming into existence depends on our actions, even though the number of people who will end up existing does not.) Moreover, I shall focus on the distribution of possible benefits rather than harms and on possible lives that would be good for the individuals who would lead them. The reason for doing so is that, plausibly, different principles apply to the distribution of benefits than to the distribution of harms and different principles may govern bringing people into existence with good lives than bringing them into existence with awful lives. ${ }^{4}$ Moreover, I shall assume a cardinal, interpersonally comparable measure of well-being derived from idealized preferences under risk. ${ }^{5}$ On this measure, when a person's chance of existence is given, a prospect has higher expected well-being for this person just in case it would be preferred for their sake after rational reflection with relevant knowledge while considering only their self-interest. One prospect has the same expected well-being as another for a person if and only if, upon such

\footnotetext{
${ }^{2}$ Jake Nebel, Priority, not Equality, for Possible People, Ethics, 127 (2017), 896-911.

${ }^{3}$ For a classic statement of the challenges posed by variable-number population ethics, see Gustaf Arrhenius, An Impossibility Theorem for Welfarist Axiologies, Economics and Philosophy, 16.2 (2000), $247-66$.

${ }^{4}$ See Jan Narveson, Utilitarianism and New Generations, Mind, 76 (1967), 62-72; Jeff McMahan, Problems of Population Theory, Ethics 92 (1981), 96-127; and Johann Frick, Conditional Reasons and the Procreation Asymmetry, Philosophical Perspectives: Ethics, 34.1 (2020), 53-84. These limitations mean that I do not consider objections to the proposed egalitarian view advanced in Toby Handfield, Egalitarianism about Expected Utility, Ethics, 128 (2018), 603-11. For the principal criticisms Handfield offers concern cases with variable populations and/or quality of life so low that it would have been better for the person never to exist.

${ }^{5}$ Such a measure is commonplace in welfare economics. See Matthew Adler, Measuring Social Welfare: An Introduction (Oxford: Oxford University Press, 2019), Sec. 2.3 and Appendix D for a defence.
} 
reflection, one would be indifferent between the two prospects. ${ }^{6}$ (I will discuss in section 3 how to conceive of a person's relevant interests when their chance of coming into existence is partly or wholly determined by our choices.) Finally, in line with orthodox decision theory, I assume that a moral decision-maker should choose the alternative with the greatest expected moral value.

\section{The moral difference between intra- and interpersonal trade-offs.}

A foundational idea of the egalitarian literature on distributive justice from the 1960s onwards is that a person's life has a unity that a mere collection of individuals lacks. This is taken to imply that distributive principles governing trade-offs between various interests of a single individual, or between alternative possible futures of the same individual, differ in key respects from principles governing trade-offs between distinct individuals' well-being. ${ }^{7}$ The unity of an individual's life gives us reason to make intrapersonal trade-offs with an eye to maximizing this individual's expected well-being, as prudence dictates. The separateness of persons requires that when people's interests conflict, we give greater weight to the interests of those who are worse off than others. To illustrate the moral significance of this difference for cases involving possible future people, consider the following case, which contains two contrasting scenarios. ${ }^{8}$

Future Child 1. Through in-vitro fertilization, a child will be born to a woman who is a stranger to us. The prospective mother will develop a condition that will not affect her well-being. But this condition will, if untreated, cause her child to develop an impairment that will manifest in early adulthood ${ }^{9}$ and cause it to have a merely tolerable quality of life (a well-being level of 30). The mother's condition comes in two types, type 1 and type 2 . The type she will develop is independent of our actions. Moreover, these types are equally likely and equally severe in their impacts on her child. We can improve the prospects of her child in one of two ways.

Option $A$ involves developing a treatment which will fully cure the child's impairment just in case the mother develops type 1 of the condition, in which case the child will have an excellent life (a well-being of 90). Unfortunately, this treatment will be ineffective in case the mother develops type 2 .

Option $B$ involves developing a treatment that is equally, and partially, effective at limiting the impact of both types of the condition. It will ensure that the child's

\footnotetext{
${ }^{6}$ In this assessment of a person's prospects from the perspective of self-interest, I set aside any interest they may have in fair distribution. I do so in order to clearly separate a person's well-being from questions of fair distribution.

${ }^{7}$ See David Gauthier, Practical Reasoning (Oxford: Clarendon Press, 1963), pp. 121-27; John Rawls, A Theory of Justice, rev. edn (Cambridge, MA: Harvard University Press, 1999), pp. 23-24; and Thomas Nagel, The Possibility of Altruism (Princeton: Princeton University Press, 1970), p. 138. For the history of this idea, see Bastian Steuwer, One-by-One: Moral Theory for Separate Persons (unpublished doctoral thesis, London School of Economics and Political Science, 2020), Introduction.

${ }^{8}$ Scenarios of this kind were first discussed in Michael Otsuka, Prioritarianism and the Separateness of Persons, Utilitas, 24 (2012), 365-80 (pp. 369-70).

${ }^{9}$ The assumption that we are morally motivated strangers ensures that we are motivated by impartial distributive ethics alone. The assumption that the health problems in question will manifest only in adulthood ensures that in the Intrapersonal Scenario, the individual's identity is constant across the different potential futures under consideration.
} 
well-being will be improved to a moderate level, which lies just below the midpoint between an excellent life and a merely tolerable life (a well-being of $60-$ $c$, with $c$ positive and small). In the Intrapersonal Scenario, precisely one embryo will be implanted and the identity of the child who will be born (Chad) is fixed. This scenario is depicted in the top section of Table 1.

In the Interpersonal Scenario, two embryos will be implanted, although only one will develop into a child. The identity of the child who will be born is independent of our choice and is equally likely to be Dylan, who will be born if the mother develops type 1, and Ed, who will be born if the mother develops type 2. This scenario is depicted in the bottom section of Table 1. (The numbers in brackets are the probabilities of the two possible states of the world, rationally calculated given the available evidence. A possible person's non-existence in a state of the world is depicted by the symbol '--'.)

On some leading views of distributive ethics, in deciding whether we should develop treatment $A$ or $B$, it makes no difference in which of these scenarios we find ourselves. ${ }^{10}$ One might attempt to justify these views' idea that these intra- and interpersonal tradeoffs under risk should be governed by the same principles as follows. In both scenarios, the life of the child if his mother turns out to have type 1 of the condition is a complete whole. Moreover, Chad's life in this state of the world is just as good as Dylan's life in this state of the world. Analogous things are true of Chad's and Ed's life if the child's mother turns out to have type 2. Moreover, in both scenarios, once the state of the world materializes, the alternative life is ruled out; in this sense, the perspective from which Chad has two futures in the intrapersonal scenario is ephemeral, as is the perspective from which both Dylan and Ed's lives are equiprobable. In terms of the ways we should trade off possible improvements to these different complete lives, it is therefore irrelevant from the impersonal moral point of view whether they are alternative possible lives of the same person (as in the Intrapersonal Scenario) or alternative lives of distinct persons (as in the Interpersonal Scenario).

In opposition to this line of reasoning, I submit that it matters in which scenario we find ourselves. In the Intrapersonal Scenario, if we choose to develop the possible full cure $(A)$, then it is a single person, Chad, who has both the opportunity of an excellent life and the chance of being left with a merely tolerable life. Moreover, this option maximizes Chad's expected well-being. Given our measure of well-being, it is the option that is most choiceworthy on Chad's behalf. Consequently, we have a prudential justification

\footnotetext{
${ }^{10}$ One view on which this would be true is utilitarianism, on which, in Future Child 1, we should choose $A$ for all $c>0$ no matter which scenario we are in, since this maximizes expected total final well-being. Another is prioritarianism for final well-being, which incorporates the following ideas: (a) increases in a person's final well-being have positive but diminishing marginal moral value; (b) the moral value of a person's final well-being depends only on their level of well-being and not on how anyone else fares; and (c) under risk, we should maximize the expected sum of the moral value of each person's final well-being. On this view, there is some $c>0$ for which we should choose $B$ in both scenarios, and the largest $c$ for which we should do so in the Intrapersonal Scenario of Future Child 1 is the same as the largest $c$ for which we should do so in the Interpersonal Scenario. For a defence of utilitarianism which considers cases of risk, see David McCarthy, Utilitarianism and Prioritarianism II, Economics and Philosophy, 24 (2008), 1-33. For a defence of final well-being prioritarianism under risk, see Wlodek Rabinowicz, Prioritarianism and Uncertainty: On the Interpersonal Addition Theorem and the Priority View, in Exploring Practical Philosophy: From Actions to Values, ed. by Dan Egonsson, Jonas Josefsson, Bjorn Petersson, and Toni Rönnow-Rasmussen, (London: Ashgate, 2001), pp. 139-65.
} 
Table 1. Final well-being in Future Child 1

\begin{tabular}{|c|c|c|c|}
\hline \multicolumn{4}{|c|}{ Intrapersonal Scenario } \\
\hline & & \multicolumn{2}{|c|}{ State of the world } \\
\hline \multicolumn{2}{|c|}{ Alternative } & Mother develops type 1 (0.5) & Mother develops type $2(0.5)$ \\
\hline$A$ & Chad & 90 & 30 \\
\hline B & Chad & $60-c$ & $60-c$ \\
\hline \multicolumn{4}{|c|}{ Interpersonal Scenario } \\
\hline & & \multicolumn{2}{|c|}{ State of the world } \\
\hline \multicolumn{2}{|c|}{ Alternative } & Mother develops type $1(0.5)$ & Mother develops type $2(0.5)$ \\
\hline$A$ & $\begin{array}{c}\text { Dylan } \\
\text { Ed }\end{array}$ & $\begin{array}{l}90 \\
--\end{array}$ & $\begin{array}{l}-- \\
30\end{array}$ \\
\hline$B$ & $\begin{array}{c}\text { Dylan } \\
\text { Ed }\end{array}$ & $\begin{array}{c}60-c \\
--\end{array}$ & $60-c$ \\
\hline
\end{tabular}

to Chad for choosing $A$. (Moreover, such a justification exists for $A$ only.) If we do so, however things turn out, we can explain that we acted for his sake by doing what, given the information available at the time, we rationally took to be in his best interests. In this way, the fact that the distinct, complete possible lives that are at stake in this scenario belong to the same person matters to the justifications available to us. Moreover, when we step back from Chad's personal perspective and consider the impersonal moral value of Chad's well-being in isolation from how anyone else fares, there is, I submit, compelling reason to simply base our assessment of this value on the amount of good we can do him. To do otherwise - for instance, to judge that an increase in Chad's well-being from 30 to $60-c$ is morally more significant than an increase from $60-c$ to 90 even though it is not more important for him and we are focusing on his well-being alone - would be to take a perspective on moral value that is curiously divorced from the interests of the only person whose fate is under consideration. We should therefore hold that expected moral value is maximized when we act to best promote Chad's interests given the information available. It follows that for every $c>0$, we have decisive reason to choose $A$ in the Intrapersonal Scenario.

By contrast, in the Interpersonal Scenario, if we pursue a potential cure, only one possible person, Dylan, would have an opportunity to benefit. For, in this scenario, this cure will work only for the condition that would affect Dylan but will be ineffective against the condition that would affect Ed. This means that, if Ed is born and the potential cure turns out to have been ineffective, we cannot offer a prudential justification to Ed for our choice. Instead, we can say only this: 'We chose to develop the possible cure because this had a chance of providing a slightly greater additional benefit to Dylan, who might have been born instead.' To this attempted justification, Ed could voice the following powerful reply: 'Instead of exclusively promoting Dylan's expected interests, you could have promoted our expected interests equally. Equal consideration of our interests is inconsistent with your setting aside all expected benefits for Dylan's possible arrival, when instead you could have divided nearly the same amount of expected benefits equally between us.' This shows that the fact that the prospective lives in the Interpersonal Scenario belong to separate individuals matters to the nature of the justifications on offer to the possible people whose quality of life is at stake. Moreover, this fact is also relevant to our 
assessment of impersonal moral value in this scenario. For in assessing this value, it is relevant that option $A$ generates a situation in which of two possible children who are equally likely to exist, one possible child has life prospects that are both poor and substantially worse than the other child's. In contrast, $B$ ensures that these potential children have equally good life prospects. For reasons I will elaborate more fully in the next section, the relative poverty of Ed's prospects under $A$ depresses the expected moral value of that alternative. ${ }^{11}$ In sum, in the Interpersonal Scenario, both consideration of interpersonal justification and impersonal moral value should, I submit, prompt us to tolerate at least a small loss of expected total well-being to improve the two potential people's prospects to an equal extent. It follows that for some, sufficiently small, positive $c$, we have decisive reason to choose $A$ in the Interpersonal Scenario.

I shall now develop a novel view which accounts for both this judgment in the Interpersonal Scenario and the contrasting purely prudential moral reasoning in the Intrapersonal Scenario.

\section{Egalitarianism for prospective people}

On a well-known egalitarian view, when we consider individuals who will certainly exist, there is a presumption that it is unfair if co-existent individuals' interests are advanced unequally. ${ }^{12}$ On this view, these interests have two aspects. The first is the value of each individual's prospects - their expected well-being. This value is relevant because it captures the extent to which a decision-maker's actions advance each person's interests as rationally perceived with the information available at the time of decision. The second aspect is each individual's final well-being. This is relevant because it represents how well their lives truly end up going, and as such the interests that a decision-maker should aim to see advanced equally, if they had full information about how individuals would be affected by their actions. On the egalitarian view in question, both senses of a person's interest are important. It is unfair if some individuals have worse prospects than others, because this means the 'deck is stacked against them'. It is also unfair if some end up worse off than others, because such inequality means that some lead worse lives than others due to factors beyond their control. ${ }^{13}$

This form of egalitarianism is pluralist, in the sense that it also embodies a concern for improving individuals' prospects and final well-being. In sum, it holds that equal concern for each person demands that we aim to (a) reduce unfair inequalities in

\footnotetext{
${ }^{11}$ Notice that, in contrast, in the Intrapersonal Scenario, Chad's prospects are moderately good under $A$ and no worse than anyone else's prospects that we are considering. These represent two further differences between choosing $A$ in the Intrapersonal Scenario and in the Interpersonal Scenario.

${ }^{12}$ G. A. Cohen, On the Currency of Egalitarian Justice, Ethics 99 (1989), 906-44; Larry Temkin, Inequality (Oxford: Oxford University Press, 1993); and Kasper Lippert-Rasmussen, Luck Egalitarianism (London: Bloomsbury Academic, 2015). In the cases I consider, there is no reason to override this presumption.

${ }^{13}$ For defences of the idea that both inequalities in chances and in final well-being matter, see Alistair Ulph, The Role of Ex Ante and Ex Post Decisions in the Valuation of a Life, Journal of Public Economics, 18 (1982), 265-76 (pp. 268-9); John Broome, Fairness, Proceedings of the Aristotelian Society, 91 (1990), 87-101; Richard Arneson, Postscript to Equality and Equal Opportunity for Welfare, in Equality: Selected Readings, ed. by Louis Pojman and Robert Westmoreland (Oxford: Oxford University Press, 1997), pp. 238-41; Larry Temkin, Inequality: A Complex, Individualistic, and Comparative Notion, Philosophical Issues, 11 (2001), 327-53; and Alex Voorhoeve and Marc Fleurbaey, Egalitarianism and the Separateness of Persons, Utilitas, 24 (2012), 381-98.
} 
prospective and final well-being between co-existents and (b) improve individuals' prospective and final well-being.

This view can explain the judgment in our Intrapersonal Scenario. Insofar as we consider Chad's prospects in isolation from how anyone else fares, inequality is not at issue. The only remaining imperative is then to maximize the value of his prospects, which requires choosing $A$. However, it cannot explain the proposed judgement in our Interpersonal Scenario. ${ }^{14}$ Since, in each possible outcome, there is only one person for us to consider, neither inequality in final well-being nor inequality in expected wellbeing between co-existents is at issue. There is, of course, the other pluralistic egalitarian imperative, to promote individuals' well-being. But it is unclear how this should be understood in this case, in which two potential individuals' interests are in competition, but there is no inequality between co-existents. This form of egalitarianism therefore requires supplementation.

In previous work, Marc Fleurbaey and I advanced the following proposal. ${ }^{15}$ Motivated by the idea that egalitarian concerns must be limited to how co-existents' prospects and fates compare, we proposed a form of pluralist egalitarianism which incorporates the following non-egalitarian idea: it is more important to improve a person's prospects, conditional on their existence, the less valuable these prospects are, even if their prospects are not worse than anyone else's.

This view arrives at the correct verdicts in our scenarios. In the Intrapersonal Scenario, it mandates $A$ because this maximizes Chad's expected well-being. In the Interpersonal Scenario, by contrast, for a sufficiently small $c$, it mandates $B$, since it holds that for $c$ small enough, it is more important to improve the quality of a person's conditional prospects from 30 to $60-c$ than to improve a person's conditional prospects from $60-c$ to 90 . Crucially, this is not on the grounds that choosing $B$ would avoid, whereas choosing $A$ would cause, objectionable inequality between Dylan's and Ed's conditional prospects. Instead, on this view, it is simply especially important to improve Ed's poor conditional prospects.

I now believe, however, that our proposal was based on too narrow a view of the scope of egalitarian concerns. It therefore fails to capture the essentially comparative reasons that, in the Interpersonal Scenario, it is natural to imagine Ed putting forward, namely, that choosing $A$ was incompatible with equal concern for each possible child, because it advanced Dylan's prospective interests only, when instead it was possible, at little cost, to have advanced both Dylan's and Ed's prospective interests equally. This reasoning can also be phrased in the following, less personal terms. Equal concern for the lives of those who, given our choices, have a chance of coming into existence requires that we adopt two broad aims: that whoever exists fares well and that the world is equally well-prepared for the arrival of whoever might come into existence. In the Interpersonal Scenario, $A$ ensures that the two children who may come into existence have grossly unequal prospects. By contrast, $B$ ensures that these two possible children have equal prospects, and it does so at only a small loss in total expected quality of life. In other words, $A$ makes the world a much more welcoming place for one of the two children who may arrive, whereas $B$ makes the world just as welcoming for any child who might arrive, at modest cost. Equal concern therefore requires that we choose $B$.

\footnotetext{
${ }^{14}$ See Otsuka, Prioritarianism, p. 370.

${ }^{15}$ Voorhoeve and Fleurbaey, Priority or Equality for Possible People? Ethics, 126 (2016), 929-54.
} 
Such reasoning is, I suggest, a natural way of explaining what makes it wrong to choose $A$ in the Interpersonal Scenario. It is also a more fitting extension of the pluralist egalitarian view under consideration than the non-egalitarian idea that an improvement in a person's prospects has diminishing marginal moral significance independently of how anyone else might fare. For it simply applies the egalitarian interpretation of equal concern - that it is important that people's lives go equally well and that their interests, as rationally perceived at the time of decision, are equally well served - to anyone who we rationally believe has a positive probability of coming into existence if we choose the option under consideration. Like standard egalitarianism, this extension is motivated by the avoidance of unfairness. In the Interpersonal Case, it would be unfair if all possible benefits were set aside for Dylan, while no such unfairness would obtain if expected benefits were split equally between Dylan and Ed. And while this idea is of course distinct from the unfairness of some co-existents being less well-off than others, it is a straightforward application of the idea that unfairness also inheres in a difference in expected well-being, because such inequality amounts to one individual's interests, as we rationally assess them with the information available at the moment of decision, being advanced more than another's. ${ }^{16}$

There is, however, one issue which does not arise when we consider inequality in expected well-being between co-existents: when we evaluate the badness of inequality in conditional prospects, we must consider the chance that the individuals in question will come into existence. To see why, suppose that we were to change the probabilities of the two states of the world in our Interpersonal Scenario so that the chance of the mother developing type 1 (and therefore the chance of Dylan coming into existence) is very large and the chance of her developing type 2 (and therefore the chance of Ed coming into existence) is very small. In that case, the inequality in conditional life prospects that a choice of $A$ would generate would seem less significant than in the scenario as it stands, in which each is equally likely to exist. When the mother will either have a child with an excellent life or a different child with a merely tolerable life, the inequality in their life prospects should be of greater concern when these possibilities are equally likely than when the first of these children is much more likely to come into existence. More generally, a future parent whose child will either lead a good life (if they lack a genetically caused ailment) or a poor life (if they have this ailment) should be much more concerned by this inequality if the children are equally likely to exist than if the former is, as one would hope, much more likely than the latter. To put it differently: when only one of two possible people will exist, in order to eliminate a given amount of inequality in conditional expected well-being between them, it is reasonable to incur a higher cost in terms of expected total well-being in order to improve the prospects of the child with poorer prospects when these individuals are equally likely to come into existence than when one is much more likely to come into existence than the other.

\section{Why conditional expected well-being?}

One may ask why the individual's relevant interests are wholly determined by how well they would fare if they came into existence and not (at least in part) by their chance of coming into existence. After all, we are supposing that the life they would lead would be good for them. Indeed, on an attractive measure of well-being, a good life is one that

\footnotetext{
${ }^{16}$ Here, I am disagreeing with Otsuka, Prioritarianism, p. 370.
} 
would be preferred for the person's sake to their non-existence and be such that their well-being level, if they came into existence, would make their life better for them than never existing. ${ }^{17}$ Wouldn't it therefore be a matter of distributive concern to ensure that individuals have equally valuable prospects of existence?

There are several reasons why the answer is no. For one, admitting an interest in coming into existence to lead a good life within an egalitarian theory of distributive ethics would seem to require that we recognize a tremendous amount of hitherto unrecognized inequality, namely between all merely possible people who will never come into existence and all individuals who will ever lead good lives. ${ }^{18}$ It would also imply that, if faced with two possible people whose chance of a good existence depends on us, we would have reason to give them a roughly equal chance of existence, even if the first of these people would, if they came into existence, have a better quality of life than the second person would, if they came into existence instead. ${ }^{19}$ These unappealing implications are avoided if, as seems sensible, we assign different moral status to, on the one hand, an individual's interest in coming into existence and, on the other, an individual's interest in having good life prospects if they come into existence. On this proposal, we have no reasons of distributive morality to promote the former, but we do have such reasons to advance the latter, and to do so equally. There are no claims on an individual's behalf to be given a higher chance of existence. But there are claims on their behalf to have the quality of their conditional prospects (and of their life, should they come into existence) promoted to an equal extent. ${ }^{20}$

The following case offers a good test of the intuitive appeal of this approach.

\footnotetext{
${ }^{17}$ For this measure of well-being, see Matthew Adler, Well-being and Fair Distribution (Cambridge: Cambridge University Press, 2012). Against such a measure of well-being, John Broome argues that if living with a high level of well-being is better for a person than never existing, then it follows that their never existing would be worse for them. But the latter, he claims, is an absurdity, since nothing can be better or worse for a person who never exists. (See John Broome, Ethics out of Economics (Cambridge: Cambridge University Press, 1999), p. 186.) For arguments against Broome's conclusion, see Gustaf Arrhenius and Wlodek Rabinowicz, The Value of Existence, in The Oxford Handbook of Value Theory, ed. by Iwao Hirose and Jonas Olson (Oxford: Oxford University Press, 2015), pp. 424-44; Fleurbaey and Voorhoeve, On the Personal and Social Value of Existence, in Weighing and Reasoning: Themes from the Work of John Broome, ed. by Iwao Hirose and Andrew Reisner (Oxford: Oxford University Press, 2015), pp. 94-109; and Hilary Greaves and John Cushbert, Comparing Existence and Non-Existence, in Ethics and Existence: The Legacy of Derek Parfit, ed. by Jeff McMahan, Tim Campbell, James Goodrich, and Ketan Ramakrishnan (Oxford: Oxford University Press, 2021). These responses to Broome's argument show that it makes sense to compare a person's existence with their nonexistence on their behalf; they do not show that we must make this comparison. A focus on conditional expected well-being might therefore be justified in a different manner than proposed in the main text, by holding that existence with a given level of well-being and non-existence are non-comparable on a person's behalf. See Jake Nebel, An Intrapersonal Addition Paradox, Ethics, 129 (2019), 309-43 (pp. 334-40).

${ }^{18}$ Krister Bykvist, Being and Well-being, in Weighing and Reasoning: Themes from the Work of John Broome, ed. by Iwao Hirose and Andrew Reisner (Oxford: Oxford University Press, 2015), pp. 87-93.

${ }^{19}$ See case 6 in Voorhoeve and Fleurbaey, Equality or Priority.

${ }^{20}$ See Melinda Roberts, Child versus Child-maker: Future Persons and Present Duties in Ethics and the Law, (Lanham, MD: Rowman \& Littlefield, 1998) and Peter Vallentyne, Review of Child versus Child-maker: Future Persons and Present Duties in Ethics and the Law by Melinda Roberts, Noûs, 34 (2000), 634-47.
} 
Future Child 2. The basic set-up is as in the Interpersonal Scenario in Future Child 1 , with the following differences. The mother has a one-third chance of having type 1 and a two-thirds chance of acquiring type 2 of the condition. If she develops type 1, the child born will be Fred, and if she develops type 2, it will be George. We can either create a treatment that would deliver greater benefits to Fred and lesser benefits to George, or instead ensure that whoever is born will have a treatment for their impairment that ensures a moderately good life, while keeping expected total well-being constant. The degree $d$ to which we skew the treatment in favour of Fred is up to us. This case is depicted in Table 2, with $0 \leq d \leq 30$.

If we choose $d=0$, we ensure equality of conditional expected well-being. But we also generate substantial inequality in the value of prospects of coming into existence, since George is twice as likely to come into existence as Fred. As we increase $d$, we introduce inequality in conditional expected well-being, but reduce inequality in individuals' prospects of coming into existence, until we reach $d=30$, which ensures equality in the value of prospects of existence, but generates substantial inequality in conditional expected well-being. Which $d$ should we choose? I submit that answering this question does not require careful balancing of two opposing egalitarian concerns. Instead, it is straightforward: we should set $d=0$, and for very similar reasons adduced in support of choosing $B$ in Future Child 1. There is no claim on Fred's behalf to be compensated for his comparatively low chance of coming into existence, but there is a claim on each possible person's behalf to have conditional prospects that are not worse than another's. It would therefore be unconscionable to set aside the majority of expected benefits for Fred, when we could instead divide the very same amount of expected benefits equally.

\section{Does equality for prospective people violate state-wise dominance?}

I shall now consider an objection raised by Nebel against the view advanced in my earlier work with Fleurbaey, which also challenges the more thoroughgoing egalitarianism advanced here. ${ }^{21}$ Consider the following case. ${ }^{22}$

Future Child 3. The basic set-up is as in the Interpersonal Scenario of Future Child 1 , except that our options are different.

Option $A$ involves providing the prospective mother with a treatment that is exceedingly effective if she develops type 1 but that will have only a very minor positive effect if she develops type 2. Moreover, the treatment ensures that, if the mother develops type 1, Hal will be born and have an exceedingly excellent quality of life (a welfare of $90+e$, with $e$ positive but small). If she develops type 2, Ian will be born and his quality of life will be just in excess of tolerable (a welfare of $30+e$ ).

Option $B$ involves providing a treatment that will ensure that Ian will be born. If his mother develops type 1 , this option ensures that Ian will have an excellent life; if she develops type 2 , he will have a merely tolerable life. This case is represented in Table 3.

\footnotetext{
${ }^{21}$ Nebel, Priority, not Equality, pp. 900-903.

${ }^{22}$ My version simplifies Nebel's Zygotic Selection Case and eliminates the following distorting aspect. In Nebel's version, the inegalitarian option involves 'doing nothing', whereas the option which eliminates inequality in conditional expected well-being carries a substantial risk of causing physical harm. This biases his case against the proposed form of egalitarianism. I avoid this bias by focusing solely on the possibility of improving a child's well-being.
} 
Table 2. Final well-being in Future Child 2

\begin{tabular}{ccc}
\hline & \multicolumn{2}{c}{ State of the world } \\
\cline { 2 - 3 } & $\begin{array}{c}\text { Mother develops type } 1 \\
(0.33)\end{array}$ & $\begin{array}{c}\text { Mother develops type } 2 \\
(0.67)\end{array}$ \\
$\begin{array}{l}\text { Alternative: choose } d, \\
\text { with } 0 \leq d \leq 30 .\end{array}$ & $60+d$ & -- \\
\hline $\begin{array}{l}\text { Fred } \\
\text { George }\end{array}$ & -- & $60-(d / 2)$ \\
\hline
\end{tabular}

Table 3. Final well-being in Future Child 3

\begin{tabular}{|c|c|c|c|}
\hline & & \multicolumn{2}{|c|}{ State of the world } \\
\hline \multicolumn{2}{|c|}{ Alternative } & Mother develops type $1(0.5)$ & Mother develops type $2(0.5)$ \\
\hline \multirow[t]{2}{*}{$A$} & $\mathrm{Hal}$ & $90+e$ & -- \\
\hline & Ian & -- & $30+e$ \\
\hline \multirow[t]{2}{*}{$B$} & Hal & -- & -- \\
\hline & Ian & 90 & 30 \\
\hline
\end{tabular}

$A$ generates substantial inequality in conditional expected well-being between the two children who might come into existence, with one potential child with excellent prospects and another with poor prospects. In contrast, $B$ involves no such inequality, since the child who will be born will have moderately good prospects. For some sufficiently small amount of extra well-being $e$, the egalitarian view proposed here therefore requires choosing $B$.

In contrast, Nebel argues as follows that we should choose $A$ for any $e>0 .^{23}$ If the mother develops type $1, A$ leads to a better outcome than $B$, because Hal would have higher final well-being than Ian would have. If the mother develops type 2, $A$ leads to a better outcome than $B$, because it is better for Ian. Nebel then appeals to state-wise dominance, which holds that if an alternative has a superior outcome no matter which state of the world materializes, then that alternative is better. He concludes that $A$ is better than $B$ and should therefore be chosen.

In reply, the proposed egalitarian view does not violate state-wise dominance. For, on this view, the value of an outcome is not wholly determined by the distribution of final well-being. Instead, it is co-determined by the final well-being in that outcome and the prospects enjoyed by both potential individuals at the time of decision. These prospects contribute to the value of the outcome, since they determine how well potential individuals' interests were served at the moment of decision, and therefore how fair this decision was. For this reason, if $e$ is sufficiently small, our egalitarian view can judge the outcome of $A$ if the mother develops type 2 to be worse than the outcome of $B$ in that state of the world. The reason is that choosing $A$ gave Ian prospects that were both poor and worse than the prospects of the other child whose existence our choice made possible. Both these factors depress the value of the outcome in which Ian is born. In contrast, choosing $B$ gave Ian moderately good prospects, which contributes positively to the value of the outcome even when Ian's final well-being is low.

\footnotetext{
${ }^{23}$ Ibid., pp. $901-03$.
} 
It follows that I reject the version of the Pareto principle which Nebel invokes to establish that $A$ leads to a better outcome than $B$ in case the mother develops type 2 , viz., the idea that if all the same people exist in an outcome and a first alternative leads to higher final well-being for all of them in that outcome than a second alternative, then the first alternative is better in that outcome. ${ }^{24}$ I reject this version because in considering only final well-being, it misses out one important aspect of the currency of distributive justice, namely, the quality of an individual's prospects. In this respect, the egalitarian view I propose is akin to standard egalitarian views that care about the distribution of chances. ${ }^{25}$ Consider, for example, a variant on the classic case in which two equally situated individuals have only a few weeks to live unless they receive a kidney transplant. We have only one kidney available, which we can either give outright to the first of them, or instead assign using a randomizing device which gives each an equal chance of receiving the kidney. Suppose that both patients are in pain, that effective pain relief can be given only once we know whether a patient is about to receive a kidney (the kind of relief prescribed will depend on whether they are about to have a transplant), and that using the randomizing device costs time. Suppose further that we decide to use the randomizing device. If the second patient were to lose out in the random draw, in terms of final well-being, both patients may be worse off than if the kidney had been assigned directly to the first patient. After all, the first patient will simply have had more time in pain before receiving the kidney, and the second patient will also have spent more time in pain and still not have the kidney. ${ }^{26}$ Nonetheless, even in this eventuality, the outcome of the random assignment is clearly better in one respect, and therefore possibly better overall, because it results from a fairer distribution of chances.

These claims about how the value of a person's chances can affect the moral value of outcomes fit with how these chances figure in interpersonal justification. In our kidney case, if the second patient loses out in the random assignment, the fact that we gave them a fair chance will be a good explanation to them for what we have done and the extra pain they have suffered. Similarly, in Future Child 3, a child's life prospects are part of what we can appeal to in justifying our actions to them. As David Wasserman notes in a well-known discussion of the ethics of having children, a person's prospects at the moment of their creation commonly figure in our justification to them of bringing them into existence. Wasserman writes: '[T]he reasons that [we] can offer the child for having brought her into a difficult and dangerous world. . . must. . . concern her own expected good. ${ }^{27}$ Pursuing this thought, Wasserman considers the case of a child who had reasonably good life prospects at the moment we ensured their creation but ends up having a difficult life (though one that is still worth living). He points out that we can offer the fact that their life prospects were reasonably good as a justification for making their existence more likely. ${ }^{28}$ It is noteworthy that, in Future Child 3, we could offer a justification along these lines to Ian for choosing $B$, but we could not offer such a justification to him for choosing $A$.

\footnotetext{
${ }^{24}$ Ibid., p. 902.

${ }^{25}$ See John Broome, Weighing Goods (Oxford: Blackwell, 1991), pp. 111-15 and H. Orri Stefansson, Fair Chance and Modal Consequentialism, Economics and Philosophy, 31 (2015), 371-95.

${ }^{26}$ Recall that, as outlined in $\mathrm{n} .6$, I exclude an individual's interest in fair distribution from their measure of final well-being.

${ }^{27}$ David Benatar and David Wasserman, Debating Procreation (New York: Oxford University Press, 2015), p. 142.

${ }^{28}$ Ibid., p. 142.
} 
In sum, contrary to Nebel, in Future Child 3, the fact that $A$ condemns Ian, should he be born, to a quality of life that is both meagre and inferior to the prospects of the other child we made possible, while $B$ both provides Ian with reasonably good life prospects and eliminates inequality in conditional life prospects, gives us good reasons to choose $B$. So long as the cost in final well-being of choosing $B$ is small, this reason may well be decisive. ${ }^{29}$

\section{Against person-affecting prioritarianism}

Nebel also proposes the following rival view, which is of independent interest.

\section{Person-affecting prioritarianism:}

(i) A person has a complaint against our choice if [and only if] both (a) there is some alternative we could have chosen under which she would have fared better [given the realized state of the world] and (b) our choice fails to maximize her expected well-being, conditional on her existence.

(ii) The strength of a person's complaint against a choice is determined by the extent to which it leaves her worse off than she would have been otherwise, and by how well off she is. A person's complaint is stronger the worse off she is.

(iii) We ought to choose the prospect against which people would have the weakest complaints, discounted by the probability that those complaints arise. If people would have no (or minimally weak) complaints against more than one prospect, then we ought to choose the impartially best [that is, the prospect with greatest expected moral value] of those. ${ }^{30}$

The motivation for this view is that we have important reasons to attend to each individual's valid claims to have their interests promoted and to satisfy the most morally significant collection of these claims. Furthermore, individuals have a claim against a choice we have made if and only if a different action we could have taken would have been better for them both (a) as things turned out and (b) in terms of their life prospects. These reasons to attend to people's claims may prompt us to depart from what generates the best consequences; but in the absence of these reasons, we should simply do what generates the best consequences. Moreover, as outlined above, Nebel

\footnotetext{
${ }^{29}$ Nebel also offers the following further argument using a twist on Future Child 3. Suppose that, in fact, the woman in question will have twins. The identity of the second actual child is fixed (let us call him Jack) and the two treatments under consideration will affect his well-being in the same way: if his mother develops type 1 , he will have a well-being of $90+e$, and if she develops type 2 , he will have a well-being of $30+e$ ( $e$ is positive and small). In other respects, $A$ and $B$ are the same as in Future Child 3. Nebel argues that this case demonstrates further problems for the proposed form of egalitarianism. For, he notes, $A$ will ensure perfect equality of outcome (either both boys will have exceedingly excellent quality of life, or both will have a tad above tolerable quality of life), whereas $B$ will generate a small degree of inequality of outcome (since Jack will always be slightly better off than Ian). But, for reasons already adduced, egalitarianism for prospective people holds there is reason to choose $B$. Nebel finds it strange that one might tolerate a bit of outcome inequality in order to greatly reduce inequality in life chances. There is, however, nothing peculiar in this judgment. Pluralist egalitarians care about inequality in final well-being and inequality in chances. They may therefore allow a slight increase in the former to greatly reduce the latter. See Ulph, The Role of Ex Ante, pp. 268-69; and Voorhoeve and Fleurbaey, Equality or Priority, pp. 937-38.

${ }^{30}$ Nebel, Priority, not Equality, pp. 907-08. Additions in square brackets are mine; Nebel's discussion suggests them, and Nebel confirmed them in conversation.
} 
believes that inequalities in conditional prospects between people who will not co-exist do not affect the value of consequences.

On this view, the reason for assigning prioritarian weighting to increments in a person's final well-being is operative only in cases in which individuals have conflicting claims to possible increments in their well-being. In this respect, and in its willingness to depart from what it holds would maximize expected impersonal good for the sake of satisfying the strongest personal claims, this view is a non-consequentialist, or deontic, form of prioritarianism. ${ }^{31}$ It stands in contrast to consequentialist forms of final wellbeing prioritarianism, on which final-well-being always has positive but diminishing marginal moral value and we ought always to maximize the sum of expected, priorityweighted final well-being. ${ }^{32}$ The differences between this consequentialist prioritarian view and Nebel's deontic prioritarian view are particularly clear in the Intrapersonal Scenario of Future Child 1, in which final well-being prioritarianism holds that we ought to choose $B$ for some $c>0 .{ }^{33}$ On Person-Affecting Prioritarianism, in contrast, in this scenario, Chad has no complaint against a choice of $A$, since that maximizes his expected well-being. But Chad would, if his mother develops type 1 , have a complaint against a choice of $B$. The view therefore holds that we ought to choose $A$.

In this judgment, Person-Affecting Prioritarianism agrees with the proposed form of egalitarianism. These views also arrive at the same judgment in our Interpersonal Scenario. On Person-Affecting Prioritarianism, if the mother develops type 2, Ed will have a complaint against $A$, which, for $c$ sufficiently small, will be stronger than Dylan's equally likely complaint against $B$, since the amount of well-being at stake for each is roughly equal and Ed's well-being would be much lower if we chose $A$. Nebel's view therefore holds that we ought to choose $B$, just like our proposed egalitarian view. ${ }^{34}$

It is easy to see that Nebel's view also agrees with the proposed form of egalitarianism in Future Child 2. However, Person-Affecting Prioritarianism naturally arrives at differing verdicts in Future Child 3. It reasons as follows, for all $e>0$. No one could have a complaint against a choice of $A$. If the mother develops type 1 , Hal has no complaint since he has a life worth living and he would not have existed otherwise. Furthermore, Ian has no complaint because he does not exist. If the mother develops type 2, Ian has no complaint since, in this state of the world, he is better off than if we had chosen $B$ and Hal has no complaint, since he does not exist. Nor could anyone have a complaint against a choice of $B$. For $B$ maximizes the conditional expected well-being of the only person who would then exist. Therefore, by clause (iii) of Person-Affecting Prioritarianism, we ought to choose the alternative that maximizes expected consequential value. According to Nebel, because neither alternative involves any inequality between co-existents, this means we should simply choose whatever maximizes expected total utility, which is $A .^{35}$

In the previous section, I explained the reasons for arriving at a different judgment in Future Child 3. To heighten the contrast between our views, I shall now consider another case which Nebel uses to illustrate his view. ${ }^{36}$

Future Child 4. This case is exactly like the Interpersonal Scenario of Future Child

1 , except that the treatments determine in which the state of the world each

\footnotetext{
${ }^{31}$ See Andrew Williams, The Priority View Bites the Dust? Utilitas, 24 (2012), 315-31.

${ }^{32}$ This form of prioritarianism is defined in $\mathrm{n} .10$.

${ }^{33}$ See Rabinowicz, Prioritarianism and Uncertainty.

${ }^{34}$ Nebel, Priority, not Equality, p. 909.

${ }^{35}$ Ibid., p. 909.

${ }^{36}$ Ibid., pp. 907-08.
} 
Table 4. Final well-being in Future Child 4

\begin{tabular}{|c|c|c|c|}
\hline & & \multicolumn{2}{|c|}{ State of the world } \\
\hline \multicolumn{2}{|c|}{ Alternative } & Mother develops type $1(0.5)$ & Mother develops type $2(0.5)$ \\
\hline \multirow[t]{2}{*}{$A$} & Dylan & 90 & -- \\
\hline & $\mathrm{Ed}$ & -- & 30 \\
\hline \multirow[t]{2}{*}{$B$} & Dylan & -- & $60-c$ \\
\hline & Ed & $60-c$ & -- \\
\hline
\end{tabular}

potential person will develop into a child. If we provide treatment $A$, then Dylan will be born (and have an excellent quality of life) just in case the mother develops type 1, and Ed will be born (and have a tolerable quality of life) just in case she develops type 2 . If we provide treatment $B$, then $\mathrm{Ed}$ will be born (and have a moderately good quality of life) just in case the mother develops type 1, and Dylan will be born (and have a moderately good quality of life) just in case the mother develops type 2. This case is depicted in Table 4 .

Nebel argues as follows that, in this case, no one could have complaints against any of the alternatives. No matter what we choose, the person who comes into existence has a life worth living. Moreover, had we chosen otherwise, he would never have existed. By clause (iii) of Person-Affecting Prioritarianism, we ought therefore to maximize expected consequential value. Because neither alternative involves inequality between co-existents, we should maximize expected total well-being, and choose $A$. $^{37}$

Nebel endorses this implication of his view, but I submit that his form of prioritarianism arrives at the wrong verdict in this case. For, contrary to Nebel, one can voice a complaint on Ed's behalf against a choice of $A$ in Future Child 4 which is akin to Ed's complaint against a choice of $A$ in the Interpersonal Scenario of Future Child 1. This complaint is, simply, that when the arrival of each was equally likely, a choice of $A$ set aside all potential benefits for one of the two possible children, when it was instead possible to divide these expected benefits equally at little cost. This complaint is not vitiated by the fact that in Future Child 4, if we choose $A$ and Ed comes into existence, he will have a life worth living that he would not have had if we had chosen otherwise. For this complaint is about how we acted to promote Dylan's and Ed's prospective interests as rationally perceived at the moment of decision and not about what ended up happening. Moreover, just as in Future Child 1, merely replying that we chose $A$ in order to secure greater aggregate expected advantage is inadequate, precisely because it fails to acknowledge the fact that this is a case in which, at the moment of decision, prospective persons' interests conflict. Indeed, since it requires choosing $A$ in Future Child 4 for all $c>0$, Nebel's view treats this case of conflicting interests just like the Intrapersonal Scenario of Future Child 1. It thereby fails to follow a primary dictum of distributive morality, which is to track the difference between intra- and interpersonal trade-offs.

In contrast, our proposed form of egalitarianism assimilates Future Child 4 to the Interpersonal Scenario of Future Child 1. It therefore captures the fact that these are both cases in which we must balance the interests of two equally likely future individuals. Equal consideration of these conflicting interests requires arranging benefits to these possible people's equal expected advantage when the cost of doing so is small.

\footnotetext{
${ }^{37}$ Ibid.
} 
It requires, in other words, that rather than giving one potential child excellent conditional prospects and leaving the other with just tolerable life chances, we ensure that both potential children have moderately good conditional prospects. ${ }^{38}$

\section{Conclusion}

The quality of possible future people's life prospects is a matter of common concern. So too, it seems to me, are inequalities in these prospects. For example, a future UK parent who is planning to have only one child, as well as anyone concerned with that future child's well-being, can rightly regret that this child's life expectancy will be lower if they are born a boy than if they are born a girl, and lower if they are born with a genetically caused impairment than if they are born a different person without such an impairment. I have articulated and defended a form of egalitarianism which reflects these concerns. The proposed view holds that we have reason to improve the life prospects of anyone who, given our actions, has a chance of coming into existence and reason to eliminate inequalities in such prospects. It holds, in other words, that we recognize the value of each prospective person and the distinctiveness of their life by striving to make the world welcoming to whoever might arrive, and equally so.

Acknowledgements. Work on this article was supported through the Bergen Centre for Ethics and Priority Setting's project 'Decision Support for Universal Health Coverage', funded by NORAD grant RAF-18/0009. This article was presented at the Australian National University, Duke University, Groningen University and the London School of Economics. I am grateful to those present and to Richard Bradley, Susanne Burri, Marc Fleurbaey, Kirsten Mann, Jake Nebel, Shlomi Segall, Andreas Schmidt, Bastian Steuwer and two anonymous referees for comments.

Competing interests. none.

\section{Appendix}

I here state one possible formalization of the form of egalitarianism for possible people proposed and contrast it with the view Fleurbaey and I have previously put forward.

Let $w_{i}^{j, k}$ be individual $i$ 's final well-being in the outcome that is generated by the choice of alternative $j$ and the occurrence of state of the world $k$. Let $p^{k}$ be the probability of state of the world $k$, and $S_{i}$ be the set of states in which individual $i$ exists. Then this individual's conditional expected well-being, if alternative $j$ is chosen, is defined as follows:

$$
\operatorname{cew}_{i}^{j}=\frac{\sum_{k \in S_{i}} p^{k} w_{i}^{j, k}}{\sum_{k \in s_{i}} p^{k}}
$$

\footnotetext{
${ }^{38}$ Nebel's view faces a further challenge: it appears to violate the transitivity of 'at least as choiceworthy as'. Consider a choice between $B$ from our Interpersonal Scenario of Future Child 1 and $B$ from Future Child 4. On Nebel's view, these are equally choiceworthy. For no matter what we choose, the person who comes into existence has a life worth living. Moreover, had we chosen otherwise, he would never have existed. By clause (iii) of Person-Affecting Prioritarianism, we ought therefore to maximize consequential value, which means we can permissibly choose either one. But we also know that, on his view, option $B$ from the Interpersonal Scenario of Future Child 1 is to be chosen over option $A$ from that scenario. Since $A$ in the Interpersonal Scenario of Future Child 1 is identical to $A$ in Future Child 4, by transitivity of 'at least as choiceworthy as', we have: in Future Child 4, $B$ is at least as choiceworthy as $A$. But as we have seen, on Nebel's view, this is not so. Such intransitivities generate well-known challenges for decision-making, including raising the question how this form of prioritarianism would choose from a set of all three alternatives. By contrast, the form of egalitarianism for prospective people outlined here respects transitivity, because it evaluates each alternative in isolation; its choiceworthiness therefore does not depend on which alternatives it is being compared with.
} 
In our earlier work, Fleurbaey and I take the relevant measure of how a person's interests in an outcome are advanced and were advanced at the time of decision to be a combination of this individual's final well-being in that outcome and their conditional expected well-being under this alternative. ${ }^{39}$ Moreover, we propose that conditional expected well-being makes a positive, but diminishing marginal contribution to this measure. The formulation we propose is $w_{i}^{j, k}+\varphi\left(c e w_{i}^{j}\right)$, with $\varphi($.$) a concave function.$

The equally distributed equivalent, or EDE, is a particularly attractive form of pluralist egalitarianism. ${ }^{40}$ Formally, let $\psi$ (.) be a concave function. When applied to this hybrid currency, a population of $n$ possible individuals and $n^{e}$ actually existing individuals, the EDE evaluates the outcome of action $j$ when state of the world $k$ materializes by the function $\psi^{-1}\left(\frac{\sum_{i \in O_{j, k}} \psi\left(w_{i}^{j, k}+\varphi\left(c e w_{i}^{j}\right)\right)}{n^{e}}\right)$, where $O_{j, k}$ is the set of all individuals who exist in that outcome. This view thus evaluates each outcome by first taking the sum of the transformed hybrid of final and conditional expected well-being for all people who exist in that outcome (and only those people) and then taking the inverse of the original transformation function. The expected value of an alternative is then simply the sum of the value of each possible outcome of that alternative, weighted by its probability:

$$
\sum_{k} p^{k} \psi^{-1}\left(\frac{\sum_{i \in O_{j, k}} \psi\left(w_{i}^{j, k}+\varphi\left(c e w_{i}^{j}\right)\right)}{n^{e}}\right)
$$

Instead of a unified measure of how a person's interests are (and have been) served in an outcome, the more thoroughly egalitarian approach I propose here maintains two separate measures: final and conditional expected well-being. In evaluating an outcome of alternative $j$ in state $k$, it takes account of the final well-being of every person who exists in that outcome. It also takes account of the conditional expected well-being of all individuals who had a positive probability of existing given the choice of $k$. Formally, the value of an outcome generated in state $k$ by action $j$ is given by $\psi^{-1}\left(\frac{\sum_{i \in O_{j, k}} \psi\left(w_{i}^{j, k}\right)}{n^{e}}\right)+\varphi^{-1}\left(\frac{\sum_{i=1}^{n} p_{i}^{j} \varphi\left(c e w_{i}^{j}\right)}{n^{e}}\right)$, where $p_{i}^{j}$ is individual $i$ 's chance of existing given the choice of $j$. The first term captures the EDE of the distribution of final well-being. The second term captures the EDE of the distribution of conditional expected well-being across all individuals who had a chance of existing, given the alternative chosen. In this second term, each individual's conditional expected wellbeing is weighted by their probability of existence, because inequality between two possible individuals matters more when these individuals are more likely to exist. The expected value of an alternative is then the probability-weighted sum of the value of its possible outcomes (since the value of the distribution of conditional expected well-being is a constant, we can leave that outside the summation):

$$
\sum_{k} p^{k} \psi^{-1}\left(\frac{\sum_{i \in O_{j, k}} \psi\left(w_{i}^{j, k}\right)}{n^{e}}\right)+\varphi^{-1}\left(\frac{\sum_{i=1}^{n} p_{i}^{j} \varphi\left(c e w_{i}^{j}\right)}{n^{e}}\right)
$$

\footnotetext{
${ }^{39}$ Voorhoeve and Fleurbaey, Equality or Priority.

${ }^{40}$ The EDE was introduced in welfare economics in Serge-Christophe Kolm, The Optimal Production of Social Justice, in Public Economics, ed. by Julius Margolis and Henri Guitton (London: Macmillan, 1969), pp. 145-200 and Anthony Atkinson, On the Measurement of Inequality, Journal of Economic Theory, 2 (1970), 244-63. On its merits as a measure of social welfare under risk, see Marc Fleurbaey, Assessing Risky Social Situations, Journal of Political Economy, 118 (2010), 649-80 and Michael Otsuka and Alex Voorhoeve, Equality versus Priority, in The Oxford Handbook of Distributive Justice, ed. by Serena Olsaretti (Oxford: Oxford University Press, 2018), pp. 65-85.
}

Cite this article: Voorhoeve A (2021). Equality for Prospective People: A Novel Statement and Defence. Utilitas 33, 304-320. https://doi.org/10.1017/S0953820821000017 